\title{
LÓPEZ Y RIVAS, GILBERTO (2013) Estudiando la contrainsurgencia de Estados Unidos. Manuales, mentalidades y uso de la antropología (Segunda edición). México: Ocean Sur. 96 pp ${ }^{1}$.
}

\section{Carlos Fazio}

Con base en dos manuales del Pentágono y una "guía cultural" de las fuerzas especiales de Estados Unidos, Gilberto López y Rivas nos entrega una obra de gran actualidad que nos permite entender, si se busca entre líneas, qué pasó en México, en el sexenio pasado, en el marco de la falsa guerra a las drogas de Felipe Calderón, y qué está ocurriendo ahora, en materia de seguridad y violencia, bajo el régimen autoritario de Enrique Peña Nieto. El texto parte del concepto "terrorismo global de Estado" para caracterizar la política violenta del capitalismo en su fase actual, y exhibe algunos rasgos neofascistas de las guerras neocoloniales de Estados Unidos y sus aliados europeos de la OTAN (Organización del Tratado del Atlántico Norte) de comienzos del siglo XXI.

Para ello, el autor recurre a una definición clásica de fascismo, formulada en 1935 por la Internacional Comunista, que plantea que "fascismo en el poder es la dictadura abierta y terrorista de los elementos más reaccionarios, más chovinistas y más imperialistas del capital financiero". Pero dado que el mundo cambió en los últimos 70 años, y que el nazifascismo respondió a realidades concretas que germinaron en Europa a partir de la primera posguerra de la pasada centuria, nos advierte que todavía no se ha generado un término más adecuado o categoría para caracterizar la violencia terrorista del capital financiero en nuestros días.

1. La presente reseña ha sido publicada previamente en el portal latinoamericano Sur y Sur (27 de junio de 2014 http://www.surysur.net). 
Entre las similitudes del fascismo clásico con los regímenes de George W. Bush y Barack Obama, López y Rivas destaca el componente militarista de las cruzadas neocoloniales actuales, la fe ciega en la tecnología bélica, el favoritismo hacia las grandes corporaciones del llamado complejo militar-industrial (con epicentro en el Pentágono), el ultra nacionalismo, el racismo genocida que aniquila pueblos enteros y el social darwinismo derivado de la imposición a sangre y fuego de las políticas neoliberales. Esos elementos, junto con la transgresión de los marcos ideológicos y políticos de la represión "legal" (la justificada por el marco jurídico tradicional), que implica la aplicación de facto de medidas de excepción, así como la utilización de métodos guerreros "no convencionales" para desestabilizar, invadir y ocupar territorialmente países y exterminar a las oposiciones políticas y la protesta social, conformarían la base del nuevo colonialismo de matriz estadunidense en curso.

Como viene anunciado en el subtítulo de la obra, y dada su profesión, Gilberto Lóez y Rivas pone énfasis en la utilización, por el Pentágono, de antropólogos y otros científicos sociales en las unidades de combate de las tropas de ocupación estadunidenses en Afganistán e Irak. El autor parte de un artículo de David Rohde en The New York Times, de octubre de 2007, que define el involucramiento de las ciencias sociales en los esfuerzos bélicos como una "nueva arma crucial en las operaciones contrainsurgentes", en el marco de un "programa experimental" del Departamento de Defensa puesto en práctica ese mismo año.

Dicho programa, que tiene sus antecedentes en el uso de antropólogos en las campañas contrainsurgentes de Estados Unidos durante la guerra de Vietnam y en el Plan Camelot experimentado en Chile a mediados de los años sesenta, llevó ahora a un sector importante de la academia estadunidense a considerarlo como una "prostitución de la disciplina".

Un año antes, la Asociación Antropológica Americana había condenado por unanimidad "el uso del conocimiento antropológico como elemento de tortura física y psicológica" en la prisión de Abu Ghraib, en Irak. No obstante lo cual, la antropóloga Montgomery McFate, creadora del programa Sistema Operativo de Investigación Humana en el Terreno del Pentágono -quien, dice Gilberto, se impuso la tarea de "educar" a los militares-, se dedicó a convencer a los estrategas de la contrainsurgencia de que "la antropología puede ser un arma más efectiva que la artillería”. Una visión cínica y beligerante que el autor no duda en calificar como propia de la "antropología mercenaria".

Como expresión de ese involucramiento de la alta burocracia académica con la maquinaria de guerra de Estados Unidos, cita la publicación, en julio de 2007, del Manual de campo de contrainsurgencia 3-24, editado por la Universidad de Chicago, la misma de la que salieron Milton Friedman y sus Chicago boys en 1973, a experimentar el aterrizaje de las políticas neoliberales en el Chile, todavía humeante el Palacio de La Moneda, tras el golpe de Estado de Richard Nixon, Henry Kissinger y el general Augusto Pinochet. 
Coordinado por el general David Petraeus, quien estuvo a cargo de las fuerzas expedicionarias de Estados Unidos en Irak, el Manual exhibe la falta de ética de ese centro de enseñanza superior y a sus "intelectuales mercenarios", en lo que David Price, citado por el autor, describió como una "prostitución de la antropología al servicio de las guerras del imperio".

En el prefacio del Manual, firmado por Petraeus y el general James Amos, del cuerpo de Marines, se adelantan algunos elementos y conceptos clave para entender el remozamiento o puesta al día de la contrainsurgencia. Entre ellos, el uso combinado de las fuerzas de combate (soldados y marinos), con habilidades asociadas con frecuencia a agencias no militares. Ello supone la cooperación y coordinación intergubernamental del Departamento de Defensa con las demás agencias de la llamada "comunidad de inteligencia" (CIA, DEA, FBI, etc.) y, también, a la Agencia para el Desarrollo Internacional de Estados Unidos (USAID, por sus siglas en inglés), que depende del Departamento de Estado, entre otras.

También resalta la necesidad de que las campañas de contrainsurgencia cuenten con "fuerzas flexibles", adaptables a las distintas circunstancias en un país dado, con líderes castrenses "agiles, bien informados y astutos culturalmente". Es decir, capaces de "comprender" las culturas de los "nativos" que se rebelan contra el orden establecido.

Debido a que desde hace más de medio siglo los sucesivos inquilinos de la Casa Blanca se abrogan el derecho de intervenir militarmente en cualquier parte del mundo, para justificar la extraterritorialidad de sus operaciones de contrainsurgencia, los actuales estrategas del Pentágono utilizan una entelequia jurídica denominada "nación huésped", cuyo gobierno "invita" a Estados Unidos a intervenir en su territorio en contra de su propio pueblo. Verbigracia, para citar un caso cercano, el México de Felipe Calderón.

Pero debido a que la nueva modalidad guerrera del Pentágono es contra lo que define como "enemigos irregulares" o "asimétricos", no contra ejércitos profesionales, el Manual incluye una serie de aspectos y tareas "no militares" que deben integrar la contrainsurgencia en su fase actual. Entre ellos, materias complejas como la gobernanza, el desarrollo económico, la administración pública y el imperio de la ley, todo lo cual se combina con las formas más conocidas de la "guerra interna", es decir, las acciones militares directas o encubiertas, la guerra psicológica, la guerra sucia, la acción cívica, el control de población, el paramilitarismo, el mercenarismo y el uso de la economía y de los medios de difusión masiva como armas de guerra.

Otros aspectos clave de la contrainsurgencia son las labores de inteligencia y el análisis y aprendizaje de la sociedad de un país objetivo, los grupos étnicos que lo habitan, la forma de gobierno, las fuerzas coercitivas del Estado, sus instituciones, cultura, lenguaje, percepciones de sus connacionales, valores, redes, creencias de la población, para lo cual 
se recurre a expertos en antropología, economía y ciencias políticas, quienes juegan un papel importante en lo que técnicamente se conoce como "Preparación de Inteligencia del Campo de Batalla”.

Todo ello busca conocer el apoyo o tolerancia de la población hacia un grupo guerrillero, un gobernante o dirigente político, sus capacidades y vulnerabilidades, sus tácticas y estrategias y formas de organización. Cada dirigente es motivo de un escrutinio detallado, que incluye su historia personal, trayectoria, creencias, ideología, temperamento, educación y un largo etcétera.

Para recabar información se utilizan todos los tipos de inteligencia: humana (que incluye la obtención de datos de periodistas, académicos, políticos, empresarios, contratistas, militares y policías del gobierno pelele o a desestabilizar); la inteligencia militar; el interrogatorio a detenidos y desertores, muchas veces a través de la tortura; la escucha telefónica y el espionaje de las redes de Internet-como quedó evidenciado con las revelaciones de Edward Snowden en torno al papel de la Agencia Nacional de Seguridad (NSA)-, a lo que se suman las formas rutinarias de obtención de información, vía el reconocimiento y la vigilancia, así como el uso de sensores, cámaras, inteligencia espacial, análisis de archivos de propiedad, financieros, del contenido de celulares y computadoras.

López y Rivas cita otro documento, el Manual del Equipo Humano sobre el Terreno, elaborado por el militar NathanFinney en 2008, que es utilizado para preparar y entrenar a especialistas militares y académicos provistos por empresas contratistas del Pentágono, que junto con soldados integran pequeños equipos compuestos de cinco a nueve personas, cuya tarea es apoyar a los comandantes en el teatro de guerra.

Es decir, aparte de las materias tradicionales que debe tomar en cuenta la comandancia: misión, enemigo, terreno y condiciones meteorológicas, tropas amigas y apoyos disponibles, son necesarios otros datos sobre la cultura local y los factores políticos, económicos y religiosos de la población, que les son proporcionados por estos equipos mixtos de soldados y civiles. Ello, porque según el Manual, "la dimensión humana es la esencia misma de la guerra irregular".

Como consigna el autor, estos pequeños equipos conformados por 5 a 9 miembros, cuentan con un líder, que por lo general es un oficial en actividad o retiro, un científico social, un procesador de información y dos analistas, y lo óptimo es que haya una mujer, alguien que hable la lengua local y otro que sea experto en el país en cuestión.

Ambos manuales son utilizados en la llamada dominación de espectro completo (full espectrum), noción diseñada por el Pentágono antes del 11 de septiembre de 2001, que abarca una política combinada donde lo militar, lo económico, lo mediático y lo cultural tienen objetivos comunes. Dado que el espectro es geográfico, espacial, social y cultural, para imponer la dominación se necesita manufacturar el consentimiento. Es 
decir, colocar en la sociedad sentidos "comunes" que mediante imágenes y una narrativa determinada refuerzan la visión del mundo del poder hegemónico, lo que deriva en masas conformistas que aceptan de manera acrítica y pasiva el mantenimiento y la reproducción del orden establecido, o, en el caso de un país y un gobernante considerado "hostil" por Washington, construyendo un enemigo a derrocar a través de medias verdades, mentiras y mitos, como parte de la guerra psicológica y las operaciones encubiertas.

Esa es la tarea que el Pentágono deja a las grandes cadenas multimedia bajo control monopólico privado, que en procesos de desestabilización como los de Cuba y Venezuela recurren al terrorismo mediático, instigando magnicidios y golpes de Estado.

Otro documento citado por el autor, que se suma a los anteriores, es la Guía para el asesor de las fuerzas especiales, que según el antropólogo David Price -parafraseando a Emily Post-, es "un manual de etiqueta de la contrainsurgencia". Para Price, el principal propósito de la Guía es instruir o entrenar a los militares para interactuar mejor con otras culturas. El documento fue elaborado para evitar el shock cultural de frágiles boinas verdes (como se denomina usualmente a los soldados de las fuerzas especiales de la Marina estadunidense).

Un cuarto documento utilizado por López y Rivas para estructurar la obra que presentamos, es el Manual de campo 31-20-3, tácticas, técnicas y procedimientos de defensa interna para las Fuerzas Especiales en el extranjero, tercero de una serie producida por el Departamento de Defensa, cuyo propósito político-militar es la defensa de los intereses nacionales estadunidenses (esto es, los intereses de las corporaciones y el acceso a territorios con valor geopolítico y a recursos geoestratégicos como el petróleo, el agua dulce, la biodiversidad y otros), por medio del asesoramiento y entrenamiento contrainsurgente de tropas de "cipayos" en la "nación huésped". Lo que nos remite, en el caso del México de Calderón y el actual, a los cursos y asesorías militares que reciben miembros de la Secretaría de la Defensa Nacional y la Secretaría de Marina.

Al respecto, el Manual echa luz sobre una serie de facetas que cubre la guerra de contrainsurgencia, entre ellas, las actividades previas a una misión intervencionista, los permisos de entrenamiento, el despliegue de tropas de elite (abierto o encubierto) en la nación huésped, los programas de instrucción de tropas, las operaciones tácticas, el control de población, las operaciones conjuntas, así como anexos que incluyen operaciones de inteligencia, fuerzas de autodefensa civil (paramilitares), establecimiento de bases, y un etcétera que incluye a los medios de difusión masiva (la prensa escrita, radial y televisiva) y por supuesto al Servicio de Información de Estados Unidos (USIA), adscrito a cada embajada de Washington en el mundo. Lo que alude a tareas de propaganda, desinformación y terrorismo mediático, en coordinación con operaciones de guerra psicológica del Pentágono. 
Cabe destacar, como señala López y Rivas en su texto, la importancia que el Manual le otorga al reclutamiento e integración de fuerzas paramilitares o irregulares, y escuadrones de la muerte, como parte integral de las actividades de contrainsurgencia. Su misión es la guerra sucia y/o el llamado "cazar-matar" utilizado por las "fuerzas amigas" como una "técnica" (sic) en operaciones de consolidación. Esto es, cazar y destruir o exterminar enemigos aislados.Cito textual: "El equipo de cazar-matar consiste en dos secciones: los cazadores y los asesinos. Los cazadores deben estar ligeramente equipados y (ser) altamente móviles. Su misión es localizar a las fuerzas enemigas mientras mantienen comunicación constante con los ejecutores, quienes están alertas y listos para entrar en acción. Cuando los cazadores hacen contacto, estos notifican a los asesinos".

Cabe destacar el énfasis del Manual sobre la misión principal de las fuerzas especiales en un país huésped: organizar, entrenar, aconsejar y desarrollar la capacidad táctica y técnica de las fuerzas militares locales, de modo que pueda derrotar a la insurgencia o el "enemigo interno" sin el involucramiento directo de Estados Unidos, y recurriendo, si es necesario, a la acción clandestina de organizaciones de civiles armados, ya sea bajo la forma paramilitar, el mercenarismo o de grupos de autodefensa.

Para el caso de México, vía la Iniciativa Mérida (2007), el esquema se utilizó bajo la pantalla de la guerra a las drogas, con la aquiescencia servil de Felipe Calderón que subordinó a la Sedena, la Semar, la Policía Federal, el Cisen y otras corporaciones del aparato de seguridad del Estado a sus contrapartes estadunidenses, con el saldo conocido: una catástrofe humanitaria. Más de 150 mil muertos, muchos asesinados de manera sumaria y extrajudicial (algunos posiblemente víctimas del llamado "cazar-matar" del manual estadunidense), 30 mil detenidos-desaparecidos y 250 mil desplazados forzosos. Con el añadido de que la guerra de contrainsurgencia estadunidense es instrumental a la estrategia de tomar el control de la "nación huésped", lo que efectivamente ocurrió en materia de seguridad e inteligencia bajo el régimen genocida de Calderón.

Mencionábamos más arriba la importancia que el Pentágono da a la lucha ideológica en el campo de la información; al papel de los medios de difusión masiva como arma estratégica y política. Un párrafo citado por López y Rivas es de suyo elocuente:"Las guerras modernas tienen lugar en espacios más allá de simplemente los elementos físicos del campo de batalla. Uno de los más importantes son los medios, en los cuales (...) la 'batalla de la narrativa' ocurrirá. Nuestros enemigos han reconocido que la percepción es tan importante para su éxito como el evento mismo (...) Al final del día, la percepción de qué ocurrió importa más, que lo que pasó realmente. Dominar la narrativa de cualquier operación, ya sea militar o de otro tipo, paga enormes dividendos. Fracasos en el terreno, mina el apoyo para nuestras políticas y operaciones, y actualmente pueden dañar la reputación del país y su posición en el mundo".

Al respecto, cabe señalar que Calderón logró imponer en las primeras planas de los 
medios "su" narrativa sobre la "guerra" a las drogas. A su vez, sus patrocinadores en Washington lograron fabricar a ratos la imagen de México como un "Estado fallido" (pérdida de control físico del territorio nacional, erosión de la autoridad gubernamental, incapacidad para interactuar con otros Estados de la comunidad internacional, crisis económica aguda, corrupción grave, incapacidad de proveer servicios públicos y cobrar impuestos), lo que les permitió desencadenar en México un acelerado proceso que, con eje en una violencia caótica y de apariencia demencial -dado que fue una violencia fríamente calculada-, derivó en una militarización, paramilitarización y mercenarización del país. Igual que antes en Colombia.

Hacia el final del texto, en el acápite sobre "el narcotráfico como arma del imperio", nuestro autor se apoya en el argentino Marcelo Colussi al señalar que Estados Unidos ha encontrado en ese campo de batalla (el de la falsa guerra a las drogas), un terreno fértil para prolongar y readecuar su estrategia de control social universal.

Una población asustada es mucho más manejable. Por eso que en regiones y países donde existen recursos geoestratégicos como petróleo, gas natural, agua dulce, biodiversidad, etcétera, y/o focos de resistencia popular, aparece el "demonio" del narcotráfico y las respuestas político-militares de Washington.En rigor, y más allá de que en Colombia y México existan traficantes de drogas ilícitas, ambos países fueron elegidos como plataformas de la guerra de contrainsurgencia y la guerra social desatada contra las distintas formas de resistencias y oposiciones políticas.

Tengo algunas dudas sobre las afirmaciones de López y Rivas acerca de que los grupos de la economía criminal tengan recursos materiales superiores a los de las Fuerzas Armadas mexicanas, por lo menos en cuanto a armamento y equipos de inteligencia se refiere. Pero coincidimos con él y con Pablo González Casanova en cuanto a que la llamada globalización neoliberal es un proceso de dominación y apropiación del mundo, en el marco de una reconversión transnacional del sistema capitalista.

En el marco de una guerra de amplio espectro o espectro completo, "la territorialidad de la dominación" -según la expresión acuñada por Ana Esther Ceceña hace más de un lustro-, combina intereses de seguridad y económicos relacionados con el acceso a zonas privilegiadas por sus materias primas y recursos estratégicos, con una acción de control directo sobre poblaciones y puntos geográficos determinantes, para los que han sido diseñados megaproyectos de infraestructura (redes multimodales de carreteras, puertos, aeropuertos, vías de ferrocarril, canales, cables de fibra óptica). Como resumió en 2007 el Observatorio Latinoamericano de Geopolítica, "se trata de transformar el territorio; adecuarlo a las nuevas mercancías, a las nuevas tecnologías y los nuevos negocios. Cuadricularlo, ordenarlo, hacerlo funcional y... productivo".

Eso es, a mi juicio, lo que ha venido ocurriendo y consolidándose de manera acelerada 
en México desde 2007 hasta el presente, y esta obra de Gilberto López y Rivas es esencial para ver cómo opera la contrainsurgencia del Pentágono para lo consecución de esos fines.

Dejé para el final las palabras de un veterano de la guerra de Irak:"He sido un asesino psicópata porque me entrenaron para matar. No nací con esa mentalidad. Fue el Cuerpo de Infantería de Marina quién me educó para que fuera un gánster de las corporaciones estadunidenses, un delincuente. Me entrenaron para cumplir ciegamente la orden del Presidente de Estados Unidos y traerle a casa lo que él pidiera, sin reparar en ninguna consideración moral. Yo era un psicópata porque nos enseñaron a disparar primero y a preguntar después, como lo haría un enfermo y no un soldado profesional que solo debe enfrentar a otro soldado. Si había que matar mujeres y a niños, lo hacíamos. Por tanto, no éramos soldados, sino mercenarios".Creo que esa confesión podría reflejar parte de lo que ha venido pasando en México, producto del entrenamiento militar del Pentágono a cuerpos de élite del Ejército, la Marina de Guerra y la Policía Federal. Muchas muertes podrían atribuirse a asesinos psicópatas que vienen actuando como mercenarios de una potencia extranjera en el territorio nacional.

Felicitaciones al autor, cuya larga y comprometida trayectoria permite constatar que el campo popular cuenta con académicos y antropólogos patriotas, que con su obra y su militancia se oponen de manera decidida al Pentágono y al poder capitalista transnacional. 